\title{
Leading change with digital technologies in education
}

JULIE MACKEY, NIKI DAVIS, and CAROLYN STUART, with BRENDON HENDERSON, KEITH RICKARD, ANNE LYE, TREVOR JEFFRIES and PETER SIMPSON

\section{KEY POINTS}

- Leading transformational change with digital technologies is challenging and many school leaders do not feel adequately equipped.

- Transformative change with digital technologies requires vision, leadership, school culture, technology planning and support, professional development, curriculum and instructional practices, funding and partnerships

- Relationships are pivotal to transformative change because high trust environments are conducive to innovation, risk taking, and learning.

- Technological innovation in a school setting is balanced by robust structures and processes, and informed by shared understanding of goals and expectations for student learning. 
Key strategies and principles for leading transformative change to enable technology-rich learning for students and teachers within the school community are described in this case-study research. The study identifies strategies employed to successfully lead e-learning innovation and integration in a school setting. The investigation was driven by the curiosity of five school leaders who sought to develop their own understanding, capability, and confidence through an in-depth and sustained inquiry in a case-study school.

\section{Introduction}

While digital technologies have been recognised as a key subtheme in future focused education (Bolstad \& Gilbert, with McDowall, Bull, Boyd, \& Hipkins, 20I2), and can be deployed to support pedagogical innovation, they frequently present complex problems for school leaders. The New Zealand Curriculum (Ministry of Education, 2007, p. 36) explicitly states that "schools should explore not only how ICT can supplement traditional ways of teaching but also how it can open up new and different ways of learning". Principals lead curriculum development, so it is essential that they understand the use of digital technologies to not only support but also transform learning, especially within the context of Ultra Fast Broadband (UFB) and the establishment of the Network for Learning $\left(\mathrm{N}_{4} \mathrm{~L}\right)$.

Digital technologies have become cheaper, easier to use, and an integral facet of school life. They hold potential for engaging learners and raising achievement, streamlining administrative processes, and strengthening connections between schools and whānau and communities. However, it is well understood that focusing on technology alone will not change learning practices or outcomes (Fullan \& Langworthy, 20I4; Sandholtz, Ringstaff, \& Dwyer, 1997), and that technology can be used to repackage but not transform existing practices. The responsibility for realising the potential of digital technologies relies on school leaders' knowledge, understanding, and strategic courage (Levin \& Schrum, 20I3). Transformative change with digital technologies requires an integrated strategy involving "infrastructure, inspiration, capability and opportunities for innovation" (Bolstad et al., 20I2, p. 59). Not all principals consider themselves adequately equipped to lead a transformative digital strategy in their schools, and recognition of this provided the catalyst for an innovative, grass-roots research project by and for principals.

This article presents some key findings from a case study, funded by the Teaching and Learning Research Initiative (TLRI), of the leadership of one school recognised for its digital innovation. Based on the principle that school-based research should represent a partnership between practitioners and academic researchers (Burton \& Brundett, 2005), the approach involved five experienced principals and one experienced deputy principal as co-researchers to ensure the case study and its outcomes are relevant to New Zealand principals. The challenge was to closely examine the leadership strategies employed at Tawa Intermediate School (TIS) under the leadership of Carolyn Stuart (now N4L Education Sector Lead) and to analyse how particular strategies and principles might inform and support a wider group of principals.

Ethical approval for this project was granted by the University of Canterbury Educational Research Human Ethics Committee. Case-study data included semistructured interviews with the principal, deputy principal, board of trustees, teachers and parents; focus groups with students and teachers; and classroom observations. The whole project team met regularly over a 2-year period, and the project meetings generated additional data via in-depth discussions between the principals and researchers, especially when each school leader identified initiatives within their own schools and sought insights from one another to inform their practice.

The project was guided by Schrum and Levin's (20I2) eight dimensions of technology leadership which emerged from an analysis of high-achieving technology-rich schools across the United States: vision, leadership, school culture, technology planning and support, professional development, curriculum, 
and instructional practices, funding and partnerships. Levin and Schrum (2013) described these dimensions as eight important interconnected parts, all of which interact and are essential to sustain successful technology integration in schools. Indeed, these dimensions extend well beyond a narrow focus on digital technologies and they firmly position technology innovation within wider principles of effective school leadership. The findings of this study also illustrate key aspects of successful school leadership identified by Robinson, Hohepa, and Lloyd (2009) in their extensive synthesis of research on school leadership; in particular, establishing goals and expectations, resourcing strategically, promoting and participating in teacher learning and development, and ensuring an orderly and supportive environment.

The following discussion will focus on school culture, leadership, and curriculum as priority considerations for principals planning and leading digitally rich education. These dimensions will be familiar to principals as they are universal in wider application across school activities. It was clear from this case study of TIS that they are also pivotal to the leadership of e-learning and digital strategies.

\section{School culture}

The in-depth analysis of the leadership of TIS indicated that the foundation underpinning innovative e-learning was an inclusive and collaborative school culture with a focus on student learning. This foundation was built slowly through intentional strategies, and the process was not without challenges, especially in the early stages of the principal's leadership, when current patterns of "how we do things here" were questioned and different expectations were introduced. Spending time establishing relationships and a supportive culture was a crucial precursor to technological innovation in this school. As McKenzie (20I4, p. 23) argues, "culture exists within relationships" and "the primary transmitters of it are those in leadership". At TIS the school culture was built on embedded principles of respectful, supportive, and trusting relationships; openness to change and risk taking; and a commitment to lifelong learning by all within the school community.

\section{Trusting and respectful relationships}

The ability to develop relational trust with and between staff is a core skill of successful leaders, and the outcomes include a positive attitude to innovation and a stronger professional community with an enhanced collective responsibility to improve learning (Robinson, Hohepa \& Lloyd, 2009). At TIS, trusting and respectful relationships were established by spending significant time with the whole staff developing shared understandings and expectations leading to an agreed staff treaty and dialogue covenant, and a student treaty. These articulated the way staff and students worked together and guided their interactions from a standpoint of shared personal responsibility. In the early days of establishing the culture these agreed expectations were explicitly employed to guide conversations and ensure individual and collective responsibility for developing collaborative relationships. By the time the research was conducted the school culture was characterised by a high level of trust, and a respectful and collaborative learning environment enacted by and for staff and students.

The principal explained very clearly that the expected behaviours were the same for adults and children in the school, and at times this required difficult but honest conversations between adults. She used the metaphor of fractals, saying:

whatever we expected children to do, we would do the same thing as adults ... The broccoli is fractal, because when you take the little bit off it it's like the whole and then you break [another bit] ... and it looks like the whole. And that was our metaphor for how we operate as a school. So it didn't matter whether the conversation was between me and the teacher, me and a board member, between children, between teachers and children, that the way that we spoke to each other actually should be the same throughout the organisation. (Principal Interview 3)

These characteristics are especially important in an environment where e-learning pervades, because technology changes the way relationships are developed, conducted, and sustained. For example, mutual respect and personal responsibility are critical in a school where BYOD (bring your own device) strategies are employed and students are encouraged to be online and to freely use digital technologies for their learning. Developing students' understanding of personal responsibility and respectful conversations counters potential cyber bullying

\section{The ability to develop relational trust with and between staff is a core skill of successful leaders, and the outcomes include a positive attitude to innovation and a stronger professional community with an enhanced collective responsibility to improve learning}


and encourages appropriate online behaviour. Technology also facilitated different levels of communication across groups in the school. For example, students emailed the principal directly, staff sent weekly emails to parents and whānau, and a great deal of planning and collaboration occurred digitally between teachers. The foundations of trust, mutual respect, and agreed ways of interacting underpinned effective communication in a digital environment.

\section{Encouraging risk taking to learn}

High levels of trust between teachers also supported risk taking, essential for any school community engaging with technology-related pedagogical innovation. Risk taking was evident and encouraged as teachers, leaders, and board of trustees (BoT) members were open to new ideas and willing to explore different technology-enabled approaches. This was not a reckless effort to try any new technology, rather teachers sensed a freedom to explore new tools and approaches with potential to engage students and improve learning. One teacher explained:

We are supported and kind of encouraged to think differently about how we deliver our teaching. We are not restricted by, you know "we do it this way", or "we have always done it this way and everyone needs to follow the line". If you have got an idea, you want to do something different, the school is very open to you doing it differently and actually going out there and trying new things.

(Teacher 4)

Teachers needed encouragement and support to take risks and be more flexible. In the early stages, the principal worked hard to swing the pendulum of innovation into action saying "you've got to stop doing what you've always done if you want to go to some different place". Teachers were reminded that their decisions affect student learning and that their practices always have to serve the goal of improving students' learning — this message provided both the impetus to change and the yardstick to evaluate changes.

Principals can be afraid to take risks or encourage risk taking amongst teachers and, as a result, new technologies are more frequently employed to sustain rather than transform existing practices. Wylie and Bonne (2014)

\section{High levels of trust between} teachers also supported risk taking, essential for any school community engaging with technology-related pedagogical innovation. reporting on a national survey of New Zealand schools, found that while there was a growing emphasis on e-learning in schools many teachers were using ICTs for individual tasks and the expected advances in the use of digital technologies for collaborative and future-oriented activities had not occurred. Similarly, the affordances of digital networks for professional networking and learning amongst teachers and principals were not being employed on the scale expected.

It was evident within the project team that principals regarded their lack of technological knowledge, understanding, and capability as barriers to progress and factors which affected their risk profile when considering digital innovation. Therefore, to harness the potential of digital technologies principals need strategies to address and mitigate the risks associated with significant financial outlay and transformative pedagogical changes.

TIS embraced change and balanced the accompanying risks through rigorous and shared decision-making processes. While new ideas were valued at all levels, teachers expected their ideas to be questioned and evaluated. School processes supported this through deliberate strategies which were introduced and coached until they became the modus operandi. For example, a distinction was made between dialogue meetings and decision meetings. Dialogue meetings provided an opportunity for teachers to prepare for the meeting and to engage in robust, constructive discussion without the pressure of making decisions and for participants to listen to other perspectives without focusing on outcomes. Decision meetings occurred when everyone understood the different perspectives and implications. This process developed a greater sense of ownership and the principal noted:

As the school matured we spent a lot more time in dialogue, which meant that once a decision was made there was much greater ownership of what was happening to move forward. (Principal, Interview 3)

Robust discussions about technology proposals occurred at BoT level too, and some matters were considered over several meetings to ensure that implications were understood. The BoT welcomed ideas to improve student learning outcomes and balanced their responsibilities to ensure sound, equitable, and safe outcomes with their support for innovation and change. The principal had worked to extend the culture of trust and openness to include the BoT.

\section{Developing capability through ongoing professional learning}

Innovation and risk taking were supported by a commitment to continuous learning and investment in teachers' professional development. As one teacher 
exclaimed, "as long as you are keen to learn I think anything is possible" (Teacher 5). This enthusiasm for personal professional learning permeated throughout the staff to include the leadership team and the BoT. The BoT supported whole school professional development and valued the learning culture amongst staff. Those interviewed recognised the way teachers were extending themselves to engage with new technologies with new future-focused approaches to teaching and learning. One BoT member noted:

I think the thing we are proud of as well I suppose is the 'software aspect' of the equation, what I mean by that is not the applications but actually the teachers and the things that make the whole thing work; just the tremendous bunch of teachers who actually get it and are pushing themselves to look at new apps or new ways that these things can enhance the existing teaching and learning process. And I think that is exciting to see. (BoT member)

Professional learning was an explicit and valued aspect of the school, and the principal was a "leader of learning" (Robinson, Hohepa \& Lloyd, 2009). She modelled her own learning (and risk taking) in a visible and nonthreatening manner, and one teacher described this in the following way:

She truly believes that all the technology is absolutely the way that learning is going and she wants to be in a leading school for $2 \mathrm{I}^{\text {st }}$ century learners and thinking. She is really open about that and really passionate about that. That is what she pushes and prioritises I think. But she also backs it up with a lot of her own ... time in reading and information and things. So she certainly ... practices what she preaches. (Teacher 3 )

This learning culture was fostered through staff meetings where new technologies were introduced and used by staff in meaningful contexts, for example using Google Docs as a live recording and collaborative planning mechanism. Learning about digital technologies was embedded in formal and informal professional contexts, and provided opportunities for teachers to develop their understanding and confidence without expectations for classroom use. Inevitably this safe learning environment resulted in many teachers seeing the potential of digital tools and then initiating new ideas and approaches in their classrooms without specific directives from the principal. Schrum and Levin (20I2) describe similar approaches and found that innovation flowed when leaders set high expectations, but did not mandate specific use of technology.

At TIS teachers were encouraged to share their learning at staff meetings and in weekly staff-led professional development sessions. Professional dialogue groups were also introduced to encourage teachers to share practices that make a difference for students; and online collaborative tools enabled teachers to share digital strategies and tools.
It was evident that, overall, teachers' willingness to learn and explore new technologies and associated pedagogies was intertwined with the characteristics of trust, mutual respect, and an understanding that risk taking was encouraged and supported. Not surprisingly there were still pockets of hesitation and resistance, healthy critique about the value of certain approaches or tools, and elements of compliance rather than whole-hearted adoption of new technologies and ideas. The principal and leadership team were sensitive to the variable levels of capability, confidence, and willingness to use new technologies and they played a crucial role in maintaining a supportive culture to enable change. This connection between culture and innovation is well recognised in the literature, for example, McKenzie (20I4) suggests positive culture allows schools "to achieve more, progress further and faster" (p. 27), while Brundrett and Duncan (2010) advocate creating an ethos for change, and supported experimentation, to enable curriculum innovation.

\section{Leadership}

Leadership is one of the eight dimensions identified by Schrum and Levin (20I2), and it also interconnects strongly with the other seven dimensions. In this brief section we focus on a selection of the key leadership strategies at TIS.

The prioritisation of establishing relationships and an agreed understanding about ways of working together ensured that the school community was well placed to focus on the key question of "Who are the adults that we want our children to become?" The outcome of the re-visioning process was the development of a new inquiry model, and a vision statement that was displayed prominently in the school and its materials. The vision started with the three charter goals, as follows,

\section{Engage! Grow! Inspire!}

At Tawa Intermediate our passion is to create a school that is relevant to the age in which we live. We believe in taking the best educational practices and blending them with the opportunities that digital technologies allow to create a 2Ist century learning environment that empowers our young people to succeed in their world.

The vision clearly articulates the desire for learning to be relevant to young people in a changing world where digital technologies feature within and beyond formal education. The vision implies that teachers will engage with evolving educational practices and emerging technologies in a landscape of continuous change and learning. At TIS this was enabled through a distributed approach to leadership whereby all staff were encouraged to lead innovation with student success as the focus. 
Strategies to connect the vision to learning experiences included the principal and senior leadership team spending time in classrooms (usually unannounced), observing, advising, and supporting classroom teachers. Teachers were asked to identify their focus for observation (recorded on a Google document in advance) and this often related to digital technologies in some way. Initially, not all teachers welcomed these spontaneous classroom observations, and some set relatively "safe" observation agendas. In addition, this "opening up" of classrooms became a feature of the school and they welcomed frequent visitors interested in seeing how digital technologies were being employed.

Leaders worked together, particularly the principal and the deputy principal responsible for managing the digital technologies, to maintain a balance between setting standards or expectations and encouraging teacher autonomy. For example, teachers were expected to send weekly class emails to whānau, and in the early stages of the research period they were required to share weekly reflections with the principal via MyPortfolio. It was clear that teachers understood the non-negotiable expectation to use digital technologies in relevant ways to support student learning. However, within that broad framework there was scope for individual choice and autonomy to implement e-learning and use different tools and approaches.

\section{Curriculum}

In line with The New Zealand Curriculum (Ministry of Education, 2007, p. 36) expectation that schools will use digital technologies to transform learning, TIS positioned technology as a means to achieve the vision of "engage, grow, inspire". Technological considerations were embedded within the annual plan and permeated curriculum planning where learning and achievement were the focus. The senior leadership team recognised the value of digital technologies to facilitate communication and collaboration, enhance access to resources, and their potential to engage priority learners and to improve educational outcomes for them. Teachers were encouraged to use digital technologies such as MyPortfolio, and later Google Docs, because they were applied in ways that improved communication and collaboration between students, between students and teachers, and between school and home.

The responsibilities for different curriculum areas and other activities across the school changed from a process driven by the allocation of management units, to one where every teacher had an assigned level of leadership within the school, with the higher levels being awarded management units. This created a shared sense of responsibility, and teachers leading small groupings were able to explore and champion different digital approaches. For example, one group of teachers, drawn from different syndicates, trialled different technology-rich inquiry models in their classrooms before sharing ideas across the school; and another initiative involved different syndicates exploring a range of reporting tools, including the use of MyPortfolio. This approach also reduced the risk as groups of teachers collaborated on the proposed changes and implemented them in a pilot situation before extending the application to the whole school.

A great deal of work was done to ensure that the school community, including the BoT, teachers, and the parent community understood the vision for employing digital technologies to create a 2Ist-century learning environment and support student learning. Teachers used technology to increase engagement and motivation; support inquiry learning; increase collaboration; provide personalised and independent learning; enhance learning in areas where teachers required additional support (for example, language learning); and support students with special educational needs. Digital technologies increased opportunities for students to revisit content, work at their own pace, and reflect on their learning. For example, in one classroom students were observed using an iPad app to record the steps they took to solve mathematics problems; the teacher and students then reviewed their metacognitive processes and strategies to build understanding. This same teacher also described how MyPortfolio allowed him to track and monitor students' learning better, and illustrated this by explaining how one child with dyslexia was able to organise her work in small steps and present it in MyPortfolio including through audio tools. Across the school, teachers also made extensive use of online feedback to comment on student work, initially through MyPortfolio and then via Google Docs where both students and teachers found the revision history and comment features particularly helpful, especially in developing writing.

Students interacted with a range of media as they developed their information and digital literacy skills, and they used digital technologies to communicate and collaborate within and beyond the school, for example, using quad blogging to provide real-time global connections and audiences for writing. It was common to see iPods, tablets, and laptops being used in a variety of ways, and in one classroom a group of students were observed using the teacher's smart phone to record a video for a presentation. Another group of students responded to Parliament's call for submissions on inquiry into 2Ist century learning by writing, filming, editing, and presenting a video on their interpretation of what it is like to be a 2Ist century learner and how schools need to 
transform. (Four students then presented a summary of their views at the select committee.) While the research did not attempt to evaluate student learning, we identified many examples of classroom practices where digital technologies were used in creative and engaging ways to support learning, and the above examples are included to illustrate that digital strategies were widespread.

\section{Discussion and recommendations}

The case study of the leadership of TIS provides an illustration of the strategic courage of one principal that was reinforced by her knowledge of digital technologies, her understanding of the importance of leadership principles, and her clear focus on improving learning outcomes for students. That courage was also evident in the research design (discussed in more depth by Davis, Mackey, \& Stuart, 2015) through which the principal opened her leadership practices to the sustained scrutiny of her peers and research partners through a series of meetings over a 2-year period. Questions from four principals with diverse leadership experiences and strengths enabled pertinent themes to emerge from the research, and these were confirmed through re-examination from different perspectives. Analyses were tested against other school contexts and varying experiences of these principals.
In summarising key findings that could be interpreted and adapted to inform leadership in other school settings we developed a "spinning top" diagram (see Figure I) to illustrate the importance of creating an environment conducive to innovation with digital technologies in education. In recognition of the dynamic, and at times challenging, activity of leading digital technology in schools, the diagram is built around the concepts of balance and momentum. In this analogy, the whole process of transformational leadership balances on the "pointy end" of authentic relationships while momentum is gained through inquiry-based practice. Relationships are also critical to all of the other activities and therefore run through the central spindle generating the energy, willingness, and ability to enact change. This was evident in TIS where strong relationships were valued and the establishment of a positive and open school culture had preceded technological changes. The core elements of the top's sphere begin with a shared understanding of the school's vision and values, and future-focused expectations. At TIS this was apparent in the shared understanding of the school's vision and expectations for how digital technologies would enable progress towards this. Therefore, e-learning and digital expectations were embedded within other school planning processes in an integrated and holistic manner, rather than standalone. These elements

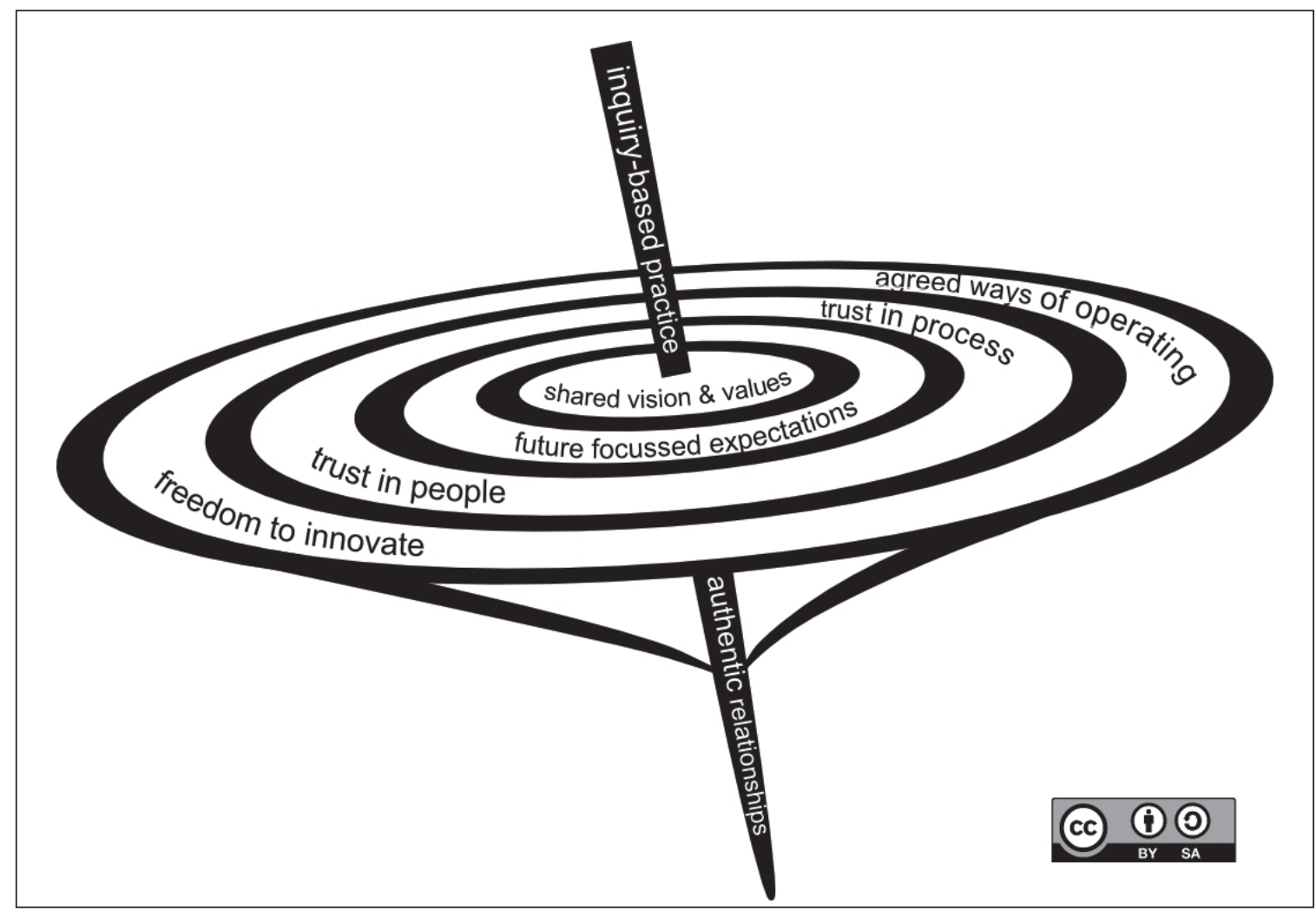

FIGURE 1. SPINNING INNOVATION: THE DYNAMICS OF LEADING INNOVATION AND CHANGE 
spin in harmony to produce a coherent vision which becomes more than the sum of the stationary parts.

The next layer of the spinning top recognises that vision and values are enabled by people and processes. Trustworthy processes encourage a willingness to enact change; for example the robust decision-making processes which preceded implementation of new technologies led to staff and board of trustees' confidence that risks had been addressed, appropriate professional development was available, and implications had been considered. The freedom to innovate emerges from the balancing factor of trust in people, and again relies very much on the centrality of well-established relationships. TIS teachers understood that they were encouraged to be proactive in their use of digital technology, and that they had the freedom to explore new approaches in the pursuit of improving student learning. Echoing the findings of Silins and Mulford (2004) in their study of organisational learning and school leadership, our study also highlighted the connections between trusting collaborative culture, shared understanding of purpose, and teacher willingness to initiate and take risks. As Robertson (20II, p. 220) states, "Trust is an essential element in the learning process, at all levels, in a learning school culture.” Hightrust environments are conducive to innovation, risk, change, and learning.

The outer rings of the circle represent some of the challenges of leadership, and Stuart (2014,), describing an earlier version of the diagram, noted that balance was achieved by teachers having the freedom to innovate within agreed structures and ways of operating:

Too much compliance will lead to bored disengagement, but innovation without the structure ...will cause an organisation to get the speed wobbles. Spinning tops with speed wobbles career away on unpredictable paths. (p. 8)

Direction and momentum were driven by the central elements of the diagram, namely vision and values, futurefocused expectations, and trust in both colleagues and processes; the combination of these factors encapsulates a willingness to contribute to the goals of improved student learning. TIS provides an example of school leadership where the top is spinning purposefully towards the vision of creating a 2Ist-century learning environment which blends the best educational practices with the alwaysemerging opportunities offered by digital technologies to empower young people to succeed in their world.

The key message for school leaders grappling with how best to lead digital initiatives in their schools is to begin with the basics of establishing strong relationships and an enabling culture before identifying how digital technologies can support the vision and enable studentfocused learning, and before launching into specific digital initiatives.
This research also demonstrated the value of principals sharing practice and spending time exploring aspects of technology leadership over a sustained period. The power of networking together in a face-to-face environment cannot be underestimated and, while the research project was supported by a virtual environment, participants were unanimous in their appreciation of the community of practice which evolved as a result of the project. Additional outcomes that spun from this particular project included initiatives in all of the principals' schools. These included the successful implementation of a BYOD programme at Churton Park School, collaboration and initiatives related to common digital technology approaches in the Levin area, and a project that investigated the benefits of oneto-one technology to engage a group of priority learners at Belfast Primary School (see Stuart et al., 20I5, for a brief discussion of these projects).

\section{Acknowledgements}

We gratefully acknowledge the funding for this 2-year project from the Teaching and Learning Research Initiative, and in particular our NZCER advisor, Sue McDowall for her support and guidance throughout the project. We would like to thank the Board of Trustees, staff, students, and parents of Tawa Intermediate School for their support and participation in this project. We also acknowledge and thank Professor Lynne Schrum, our valued critical friend throughout the project; our wonderful research assistant Pinelopi Zaka; and our dedicated summer scholar Donald Hilson.

\section{References}

Bolstad, R., \& Gilbert, J., with McDowall, S. Bull, A. Boyd, S., \& Hipkins, R. (2012). Supporting future-oriented learning \& teaching: A New Zealand perspective. [Report to the Ministry of Education.] Wellington: New Zealand Council for Educational Research.

Brundrett, M., \& Duncan, D. (20II). Leading curriculum innovation in primary schools. Management in Education, 25(3), II9-I24. http://dx.doi.org/I0.II77/0892020610387957

Burton, N., \& Brundrett, M. (2005). Leading the curriculum in the primary school. London: Sage. http://dx.doi. org/I0.4135/9781446211786

Davis, N., Mackey, J., \& Stuart, C. (2015, April). Leadership strategies for a future focused intermediate school: A case study. Paper presented at the American Educational Research Association Annual Conference, Chicago.

Fullan, M., \& Langworthy, M. (20I4). A rich seam: How new pedagogies find deep learning. London: Pearson.

Levin, B. \& Schrum, L. (2013). Using systems thinking to leverage technology for school improvement: Lessons learned from award winning secondary schools/districts. Journal 
of Research on Technology in Education, 46(I), 29-5I. http:// dx.doi.org/I0.1080/15391523.2013.10782612

McKenzie, D. (2014, September). The eight continuums of school culture. New Zealand Principal. 23-27.

Ministry of Education. (2007). The New Zealand curriculum. Wellington: Learning Media.

Robertson, J. (20II). Partnership in leadership and learning. In J. Robertson \& H. Timperley (Eds.), Leadership and learning (pp. 213-226). London, England: Sage Publications. http:// dx.doi.org/IO.4I35/978I446288931

Robinson, V., Hohepa, M., \& Lloyd, C. (2009). Best evidence synthesis iteration (BES): School leadership and student outcomes - Identifying what works and why. Wellington: Ministry of Education.

Sandholtz, J. H., Ringstaff, C., \& Dwyer, D. C. (1997). Teaching with technology: Creating student-centered classrooms. New York, NY: Teachers College Press.

Schrum, L., \& Levin, B. (20I2). Evidence-based strategies for leading 2Ist century schools. Thousand Oaks, CA: Corwin.

Silins, H., \& Mulford, B. (2004). Schools as learning organisations: Effects on teacher leadership and student outcomes. School Effectiveness and School Improvement: An International Journal of Research, Policy and Practice, 15:3-4, 43-466. http://dx.doi.org/IO.I080/092434505I2331383272

Stuart, C. (2014). Six keys for digital leadership. New Zealand Principal, November, 6-8.

Stuart, C., Henderson, B., Lye, A., Jeffries, T., Rickard, K., Simpson, P., Mackey, J., \& Davis, N. (2015). Extending innovative leadership to enable e-learning for better student outcomes in primary schools. New Zealand Principal, 30(I), IO-I2.

Wylie, C., \& Bonne, L. (20I4). Primary and intermediate schools in 2013. Main findings from the NZCER national survey. Wellington: New Zealand Council for Educational Research. Retrieved from http://www.nzcer.org.nz/system/ files/NZCER\%2oSurvey\%20Report\%20Final\%2oweb_o.pdf

Dr Niki Davis is Distinguished Professor of e-Learning at the University of Canterbury and recognised internationally as a leading expert in information and communication technologies in teacher education.

Email: niki.davis@canterbury.ac.nz

Dr Julie Mackey is academic dean for the College of Education, University of Canterbury, and a senior research fellow in the University of Canterbury e-Learning Lab.

Email: julie.mackey@canterbury.ac.nz

Carolyn Stuart, formerly principal of Tawa Intermediate School, is the education sector lead for the Network for Learning. Email: Carolyn.stuart@n4l.co.nz 